\title{
Subchronic Toxicity Studies of Methanol Extract of Eucalyptus Camaldulensis (Leaf) In Wister Rats
}

\author{
${ }^{1}$ Kabiru, Y.A, ${ }^{2}$ Okogun, J.I, ${ }^{3}$ Gbodi, T.A, ${ }^{1}$ Makun, H.A And ${ }^{1,4}$ Ogbadoyi, E.O \\ ${ }^{1}$ Department of Biochemistry, Federal University of Technology, Minna, Nigeria. \\ ${ }^{2}$ Department of Medicinal Plant Chemistry and Traditional Medicine, National Institute for Pharmaceutical \\ Research and Development, Abuja, Nigeria. \\ ${ }^{3}$ Department of Biochemistry, Ibrahim Badamasi Babangida University, Lapai, Nigeria. \\ ${ }^{4}$ Global Institute for Bio-Exploration (GIBEX), F. U. T. Minna, Nigeria.
}

\begin{abstract}
In Recent Times, Focus On Plant Research Has Increased All Over The World And A Large Body Of Evidence Has Been Collected To Show Immense Potential Of Medicinal Plants Used In Various Traditional Systems, But The Need To Evaluate The Safety Of These Plants Remains Paramount. The Sub Chronic Toxicity Of The Methanol Extract Of The Leaves Of Eucalyptus Camaldulensis, A Plant That Is Used Locally To Treat Feverish Conditions In Nigeria, Was Investigated In Wister Rats. A Uniform Dose Of The Extract $(200 \mathrm{mg} / \mathrm{Kg}$ Bodyweight) Was Administered To Healthy Wister Rats For Three Weeks, Thereafter Monitored For Another Two Weeks And Then Sacrificed To Determine Some Haematological And Histopathological Parameters Related To Sub Chronic Toxicity. There Were Significant Increases In The Mean Terminal Bodyweights, Mean $\%$ Packed Cell Volume, And Mean \% Eosinophils, While Mean \% Basophils And Mean \% Neutrophils Indicated Significant Decreases In The Test Groups. There Was No Significant Difference Between The Aspartate Amino Transaminase Activities Of Animals In The Control (24.89 \pm 1.25 IU/L) And Test (24.22 \pm 0.67 IU/L) Groups, But The Alanine Aminotransferase Activities Was Significantly Lower (16.36 \pm 2.44 IU/L) In The Test Group Than The Control (19.36 $\pm 2.12 \mathrm{IU} / \mathrm{L})$. The Mean Concentrations Of The Electrolytes $\left(\mathrm{Cl}^{-}, \mathrm{K}^{+}, \mathrm{Na}^{+}, \mathrm{HCO3}^{-}\right)$ Determined For The Test And Control Groups Did Not Show Any Significant Differences Between The Values Except For $\mathrm{Na}+(126 \pm 5.29 \mathrm{Mmol} / \mathrm{L}$ For Test And $133.67 \pm 3.21 \mathrm{Mmol} / \mathrm{L}$ For Control $)$ At P $\leq 0.5$. The Levels Of Urea $(3.6 \pm 0.6 \mathrm{Mmol} / \mathrm{L})$ And $3.7 \pm 0.66 \mathrm{Mmol} / \mathrm{L}) ;$ And Creatinine $(92.33 \pm 6.43 \mathrm{Mmol} / \mathrm{L})$ And $(99 \pm 2.65$ Mmol/L) For The Test And Control Groups Were Not Significantly Different $P \leq 0.5$. The Histopathology Of The Kidney Revealed That The Glomeruli Apparatus Were Intact But There Appeared To Be Necrosis Of The Cortex, While The Liver Monograph Showed There Was Normal Hepatic Architecture Showing Central Vein And Portal Tract Interphase With Hepatic Plates Separated By Sinusoids. Results Obtained In This Study Show That The Methanol Extract Of Eucalyptus Camaldulensis Though Reported To Have Medicinal Potential May Have Long-Term Effects On The Kidney.
\end{abstract}

Key Words: Eucalyptus Camaldulensis, Sub Chronic Toxicity, Liver, Kidney, Alanine Amino Transferase, Aspartate Amino Transaminase

\section{Introduction}

Traditional medical remedies for several diseases abound in most endemic regions. Many of these preparations have been used extensively and knowledge about them has been accrued by several generations of practitioners from experience, trial and error. In some Asian and African countries, up to $80 \%$ of the population relies on traditional medicine for their primary health care needs. When adopted outside of its traditional culture, traditional medicine is often called complementary and alternative medicine [1]. The WHO also notes, though, that "inappropriate use of traditional medicines or practices can have negative or dangerous effects" and that "further research is needed to ascertain the efficacy and safety" of several of the practices and medicinal plants used by traditional medicine systems [1] Most medicinal plants have not been thoroughly evaluated for their toxicity profiles. This notwithstanding, it is generally agreed that medicinal plants and their products are relatively safer than their synthetic counterpart drugs. The reasons for this may not be far -fetched. First, medicinal plant constituents mimic more closely the natural constitution of the human somatic system, and following the lock and key hypothesis, it is expected that they will fit better into such system. For instance, digitalis leaf is still preferred to the pure compounds (digoxin or digitoxin) as a worldwide remedy for Congestive Heart Failure (CHF) due to the higher toxicity profile of the pure compound [2]. Secondly, in terms of environmental friendliness, medicinal plants and their products are far more advantageous than orthodox medicines since they constitute a lesser form of pollution menace and are renewable. 
However a blanket assumption should not be made about the safety of medicinal plants and their products. It is necessary to ensure a thorough and detailed pharmacological and toxicological assessment of these plants and their products before approving them for therapeutic purposes. These assessments should be paramount in order to avoid "Medicinal plants mis - adventuring" of the past when seemingly innocuous plants may turn out to be toxic [2].Medicinal herbs are moving from fringe to mainstream use with a greater number of people seeking remedies and health approaches free from side effects caused by synthetic chemicals. Recently, considerable attention has been paid to utilize eco-friendly and bio- friendly plant-based products for the prevention and cure of different human diseases.Considering the adverse effects of synthetic drugs, the Western population is looking for natural remedies which are safe and effective. It is documented that $80 \%$ of the World's population has faith in traditional medicine, particularly plant-based remedies for their primary healthcare [3] [4].Based on the recognition accorded traditional medicines by the World Health Organization (WHO) when its traditional medicine programme was established, it has been argued that traditional medicines should be evaluated as they are used traditionally, in the hope of finding remedies that can be prepared and used locally at very low cost [5]. Eucalyptus (Myrtaceae), an Australian native, represented by around 700 species is a genus of tall, evergreen and magnificent trees cultivated the world over for its oil, gum, pulp, timber, medicine and aesthetic value. Among the various wood and non-wood products, essential oil found in its foliage is the most important one and finds extensive use in food, perfumery and pharmaceutical industry. In addition, the oil possesses a wide spectrum of biological activity including anti-microbial, fungicidal, insecticidal/insect repellent, herbicidal, acaricidal, and nematicidal [6].

\subsection{Plant Material}

\section{Materials and Methods}

Eucalyptus Camaldulensis (NIPRD/H/6263) was collected from the Education Resource Center/ETF ground in Minna, Niger State, between the months of June and July. The plant was identified and assigned specimen voucher number at the herbarium of the National Institute for Pharmaceutical Research and Development, Abuja, Nigeria.

\subsection{Experimental Animals}

Wister rats, used for the sub chronic toxicity studies, were purchased from Jos, Plateau State, Nigeria. The experiments involving the animals were conducted in compliance with the internationally accepted principles for laboratory animal use and care as contained in the Canadian Council on Animal Care guidelines on animal use protocol review [7].

\subsection{Preparation of Plant Sample and extraction}

These were done according to the method described by [8]. The leaves of E. Camaldulensis were removed fresh, washed with running tap water and dried at room temperature. The dried leaves were blended into powdered form using mortar and pestle, and finally in an electric blending machine. The powdered sample was then stored in clean polythene bags. Fifty $(50 \mathrm{~g})$ grams of the powdered sample was then extracted under reflux with $300 \mathrm{ml}$ of methanol for two hour. The hot extract was filtered with cheese cloth to obtain the filtrate that was subsequently evaporated using a rotary evaporator. The semi-dried extract was weighed and stored in a sample bottle until required for use.

\subsection{Sub-Chronic Toxicity Studies of $E$. camaldulensis (leaf)}

The sub-chronic toxicity study of the extract was carried out according to the format described by Gamaliel, 2000. Two groups, A and B, consisting of five rats each, were set up. Group A was administered $200 \mathrm{mg} / \mathrm{kg}$ body weight per day of the extract repeatedly for three weeks. Group B, which served as control, was administered physiological saline for three weeks. Both groups were monitored for six weeks.

\subsection{Determination of percentage packed cell volume and differential leukocyte counts}

The determination was carried out according to the method described by [9]. A small volume of blood was collected from the tail of animals in the test and control groups into a heparinised capillary tube, one end of which was sealed with plasticine and then spun for $5 \mathrm{~min}$ in a micro-haematocrit centrifuge. The Packed Cell Volume (PCV) was determined with the aid of micro-haematocrit reader, which gave the value of percentage. The differential leukocyte counts (basophils, eosinophils, and neutrophils) were determined by making blood smear on a glass slide and staining with a dye to allow for identification and counting. 


\subsection{Weight determination}

The weights of the rats were determined twice a week on a chemical weighing balance. This was done by zeroing an empty beaker in a chemical balance and then, placing each rat in the beaker to determine the weight in grams.

\subsection{Liver function test}

The animals were sacrificed at the end of study period and blood was withdrawn from the punctured heart into clean, sterile centrifuge tubes and spun. The serum obtained after centrifugation was used to determine the activities of alanine amino transferase (ALT) and Aspartate amino transferase (AST).

\subsection{Determination of Alanine Amino Transferase (ALT) Activity}

The assay method used for the determination of SGPT activity was based on the one described by [10]. The working reagent was reconstituted by mixing Reagent 2 (R2) with the volume of Reagent 1 (R1) as indicated on the vial label. To $0.1 \mathrm{ml}$ of the serum sample, $1.0 \mathrm{ml}$ of the working reagent was added. The mixture was incubated at $37^{\circ} \mathrm{C}$ for 1 minute, after which the change in absorbance per minute $(\mathrm{OD} / \mathrm{min}$.) at $340 \mathrm{~nm}$ was measured during the next 3 minutes.
ALT activity $(\mathrm{U} / \mathrm{L})=($
$\mathrm{OD} / \mathrm{min}) \times 1768$
L-Alanine $+\alpha$-ketoglutarate ALT Pyruvate + L-Glutamate

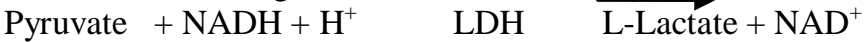

$\mathrm{NADH}$ is oxidized to $\mathrm{NAD}^{+}$, the resulting decrease in absorbance at $340 \mathrm{~nm}$ is directly proportional to the activity of ALT in the sample.

\subsection{Determination of Aspartate AminoTransferase (AST) Activity}

The method employed in this determination is a modified formulation for the assay of AST as recommended by [11]. The IFCC reference method includes pyridoxal phosphate (PP), which functions as a coenzyme in amino acid (AA) transfer. This results in increased enzyme activity, avoiding falsely low values in samples containing insufficient endogenous PP, for example from patients with myocardial infarction, liver disease and intensive care patients.

In this method, $1.0 \mathrm{ml}$ of Reagent $1(\mathrm{R} 1)$ was added to $0.2 \mathrm{ml}$ of the serum sample and allowed to incubate at $25^{\circ} \mathrm{C}$ for approximately 5 minutes. Then, $0.25 \mathrm{ml}$ of Reagent 2 (R2) was added to the test tube and allowed to mix. After 1min., the absorbance was read against air at $340 \mathrm{~nm}$. The absorbance was again measured after exactly 1 , 2 , and 3 minutes.

The enzyme, AST, is present in all tissues, but mainly in the liver, where it catalyses the following transamination reaction:

L-Aspartate + 2-Oxoglutarate $\longrightarrow$ Oxaloacetate + L- Glutamate

Oxaloacetate $+\mathrm{NADH}+\mathrm{H}^{+} \longrightarrow$ - Malate + NAD

$\mathrm{NADH}$ is oxidized to $\mathrm{NAD}^{+}$, the resulting decrease in absorbance at $340 \mathrm{~nm}$ is directly proportional to the activity of AST in the sample.

$\mathrm{AST}$ activity $(\mathrm{IU} / \mathrm{L})=\mathrm{OD}_{\mathrm{O} / \mathrm{min}} \times 1151$

\subsection{Kidney Function test}

The serum obtained after spinning of blood was subjected to tests to determine the levels of Creatinine, Urea, Potassium $\left(\mathrm{K}^{+}\right)$, Sodium $\left(\mathrm{Na}^{+}\right)$, Chloride $\left(\mathrm{Cl}^{-}\right)$, and Bicarbonate $\left(\mathrm{HCO}_{3}{ }^{-}\right)$.

\subsection{Preparation of Tissues for Histopathological Studies}

The tissues were prepared according to the method described by [12]. At the end of the study period, animals in test and control groups were sacrificed the livers and kidneys carefully removed. These organs were processed, sectioned and stained according to standard laboratory methods. They were fixed in $10 \%$ formalinsaline and 3-4mm thick tissue was cut from each organ for processing. The cut tissues were transferred to the automatic tissue processor where the tissues were further fixed in $10 \%$ buffered formol- saline for two hours and dehydrated for two hours in each ascending grades of alcohol $(70 \%, 90 \%$, and $100 \% \mathrm{v} / \mathrm{v})$. The dehydrated tissues were then cleared in xylene for two hours and the tissues impregnated in molten paraffin wax for another two hours and left to cool. The sections were then trimmed and sectioned on the microtome at 5 microns $(\mu)$. The sections were floated out in a warm water bath, then attached to slides, and dried on a hot plate and stained. The slides were viewed on a microscope with the assistance of a pathologist to enable interpretation of morphological changes in the tissues. 


\subsection{Initial and Terminal weights}

\section{Results}

There was substantial increase in the mean weights of both the test and control groups as shown in Figure1. The mean weight of the test group increased from $206.06 \pm 120$ to $214.33 \pm 125 \mathrm{~g}$, while that of the control increased from $184.66 \pm 23$ to $188.66 \pm 25 \mathrm{~g}$.

\subsection{Initial and Terminal percentage packed cell volumes (\% PCV)}

Figure 2 shows the percentage packed cell volumes (\% PCV) for both the test and control groups increased by about $2.5 \%$. For the test group, the mean \% PCV increased from $35.66 \pm 10 \%$ to $36.66 \pm 9.0 \%$ after four weeks. The control group had an increase from $39 \pm 12$ to $40 \pm 7.5 \%$.

\subsection{Differential Leucocytes Counts (\%)}

The results for the differential leucocytes counts in percentages (\%) for the test and control groups before the administration of extract and at the end of study period are shown on figures 3 and 4 . The mean $\%$ basophils for the test and control groups decreased from $49.64 \pm 6.34$ to $42.22 \pm 3.13 \%$ and from $43.48 \pm 1.5$ to $41.45 \pm 5.4 \%$ respectively. The mean \% eosinophils increased from $16.73 \pm 2.55$ to $23.89 \pm 6.35 \%$ for the test group and from $19.7 \pm 2.94$ to $22.62 \pm 3.84 \%$ for the control group. The mean \% neutrophils decreased from $33.58 \pm 3.95 \%$ to $32.19 \pm 6.02$ for the test group and from $36.8 \pm 7.38$ to $35.92 \pm 6.23 \%$ for the control group.

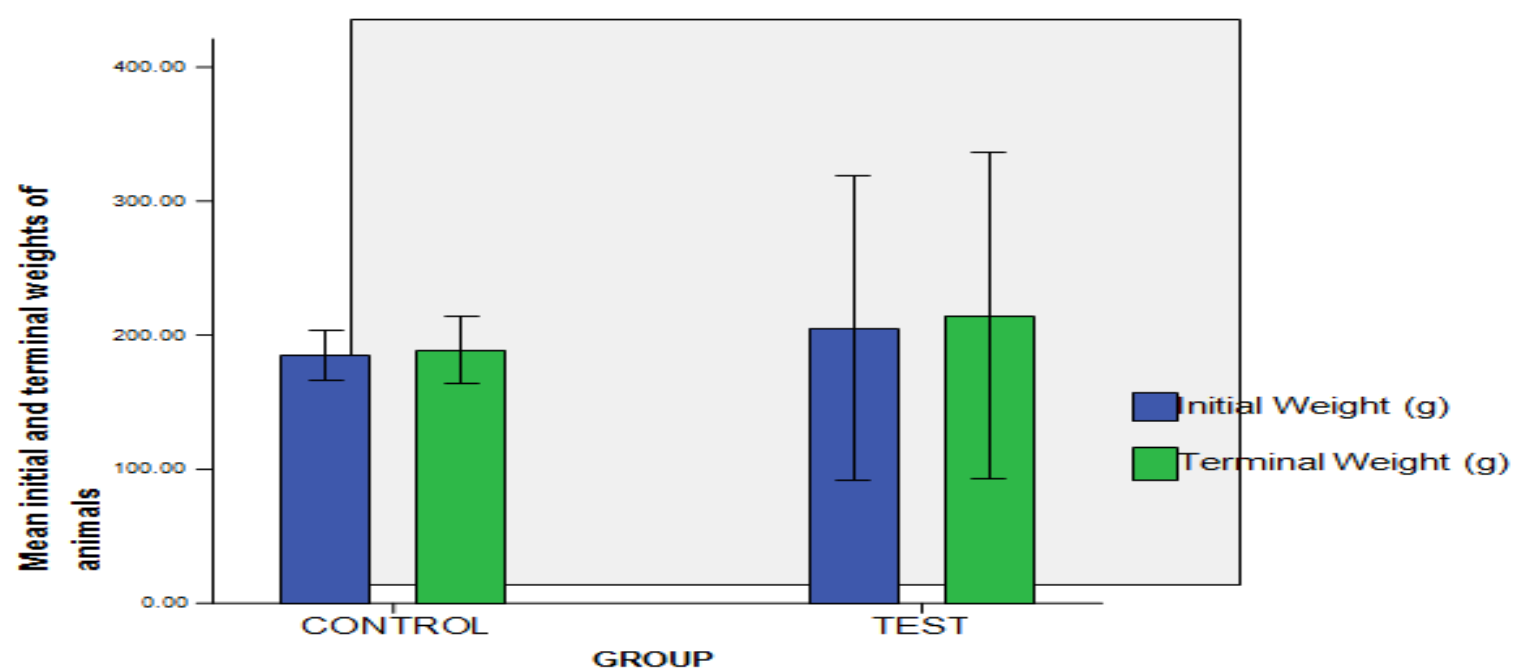

Figure 1: Initial and Terminal Weights of animals in the test and control groups

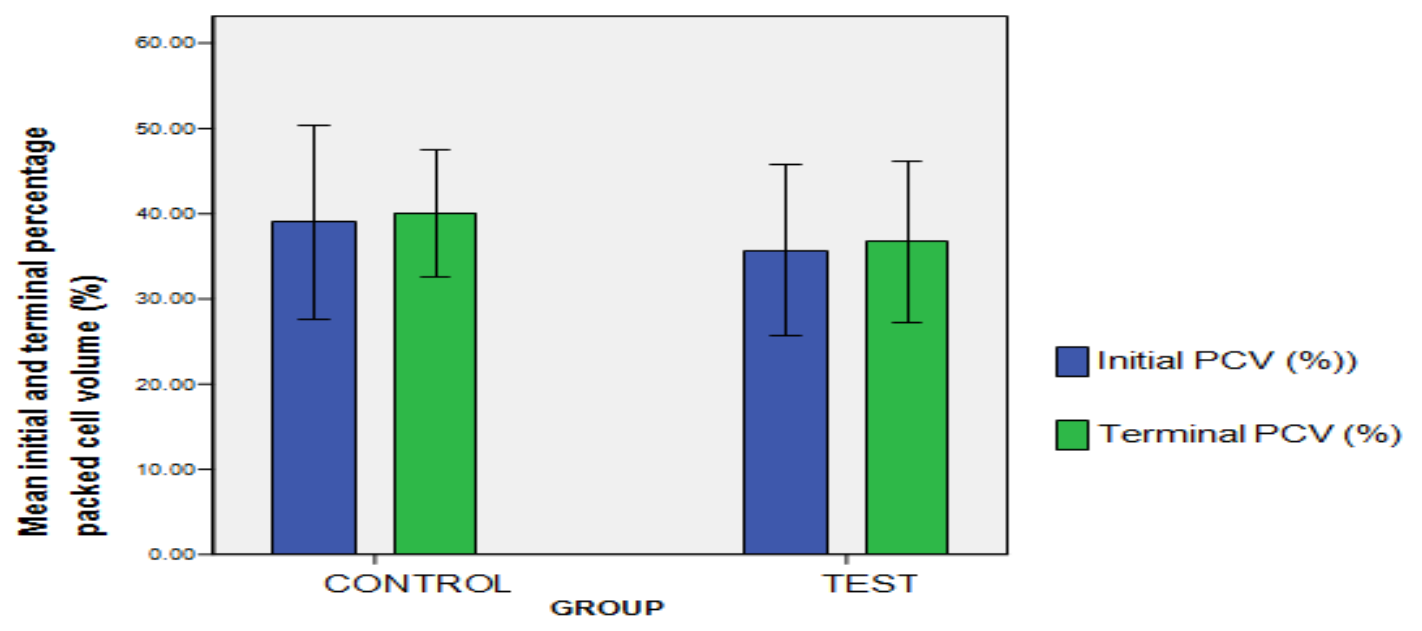

Figure 2: Initial and Terminal percentage packed cell volume of animals in the test and control groups 


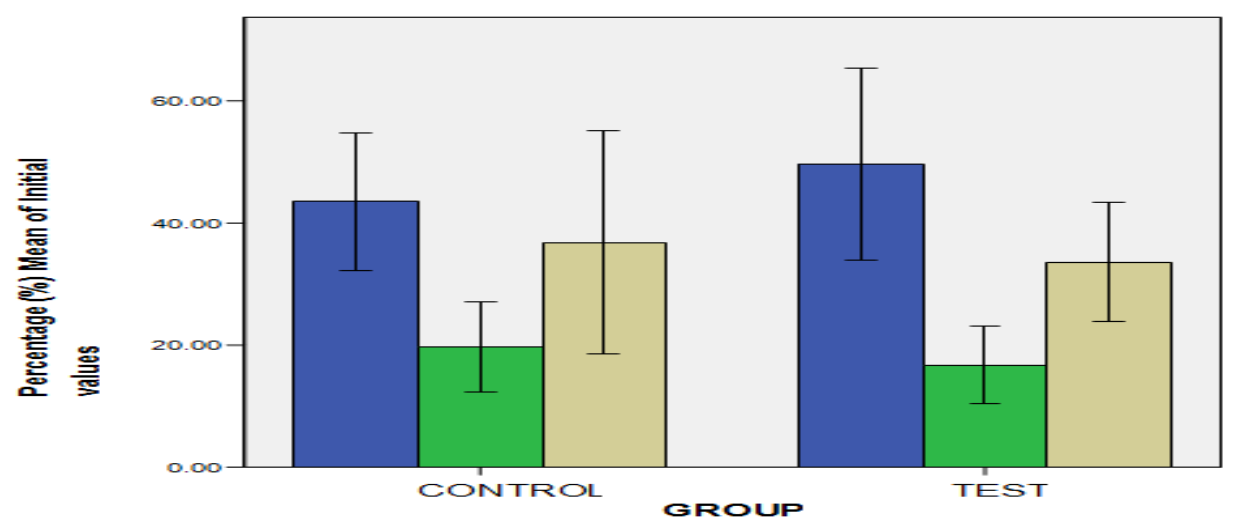

Figure 3: Initial Differential Leucocytes Counts (\%) In The Test And Control Groups

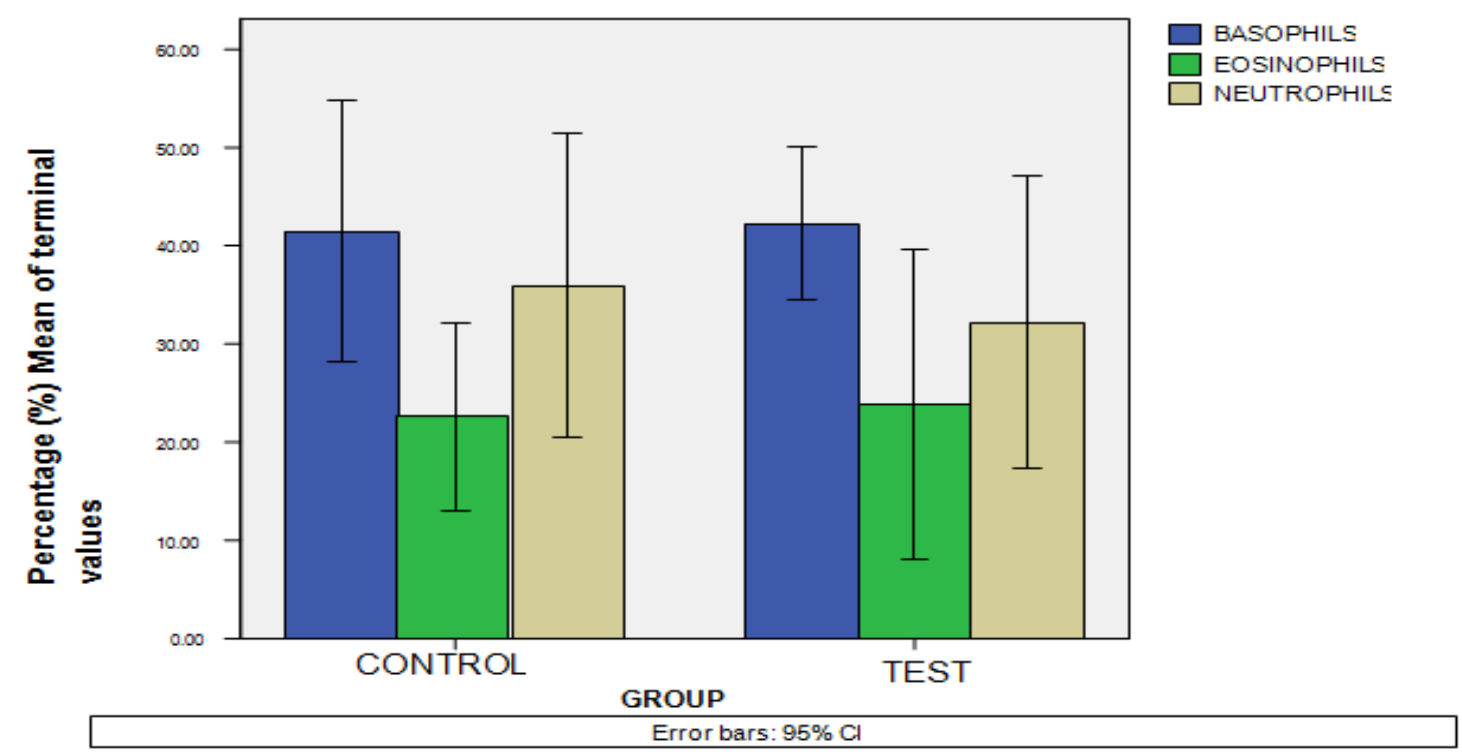

Figure 4: Terminal Differential Leucocytes Counts (\%) In The Test And Control Groups

\subsection{Activities of ALT and AST}

The activities of Alanine Amino Transaminase (ALT) or Serum Glutamate-Pyruvate Transaminase (SGPT) and Aspartate Amino Transferase (AST) or Serum Glutamate - Oxaloacetate Transaminase (SGOT) are shown on figure 5 for both the control and test groups. There was no significant difference between the ALT activities of animals in the control $(24.89 \pm 1.25 \mathrm{IU} / \mathrm{L})$ and test $(24.22 \pm 0.67 \mathrm{IU} / \mathrm{L})$ groups. The AST activities for the control $(19.36 \pm 2.12 \mathrm{IU} / \mathrm{L})$ and test $(16.36 \pm 2.44 \mathrm{IU} / \mathrm{L})$ groups were significantly different $\mathrm{p} \leq 0.5$.

\subsection{Concentrations of Serum electrolytes, Creatinine and Urea}

The serum concentrations of electrolytes, creatinine, and urea for the test and control groups at the end of the study period are presented in figure 5. The mean serum concentration of chloride $\left(\mathrm{Cl}^{-9}\right.$ ion for the test group $(101 \pm 1.0 \mathrm{mmol} / \mathrm{L})$ was not significantly different from the value for the control $(101.33 \pm 0.57 \mathrm{mmol} / \mathrm{L})$. The mean values for potassium $\left(\mathrm{K}^{+}\right)$for the test $(5.36 \pm 0.21 \mathrm{mmol} / \mathrm{L})$ was also not significantly different from that of the control $(5.13 \pm 0.12 \mathrm{mmol} / \mathrm{L})$, while the concentration of sodium $\left(\mathrm{Na}^{+}\right)$for the test $(126 \pm 5.29$ $\mathrm{mmol} / \mathrm{L})$ was significantly different from the mean value for the control $(133.67 \pm 3.21 \mathrm{mmol} / \mathrm{L})$. The bicarbonate concentration for the control $(23.33 \pm 0.58 \mathrm{mmol} / \mathrm{L})$ and test $(21.33 \pm 2.08 \mathrm{mmol} / \mathrm{L})$ groups were not significantly different $(\mathrm{p} \leq 0.5)$. The levels of urea for the test $(3.6 \pm 0.6 \mathrm{mmol} / \mathrm{L})$ and the control $(3.7 \pm 0.66$ $\mathrm{mmol} / \mathrm{L})$; the creatinine concentrations for the test $(92.33 \pm 6.43 \mathrm{mmol} / \mathrm{L})$ and control $(99 \pm 2.65 \mathrm{mmol} / \mathrm{L})$ were not significantly different $(\mathrm{p} \leq 0.5)$. 


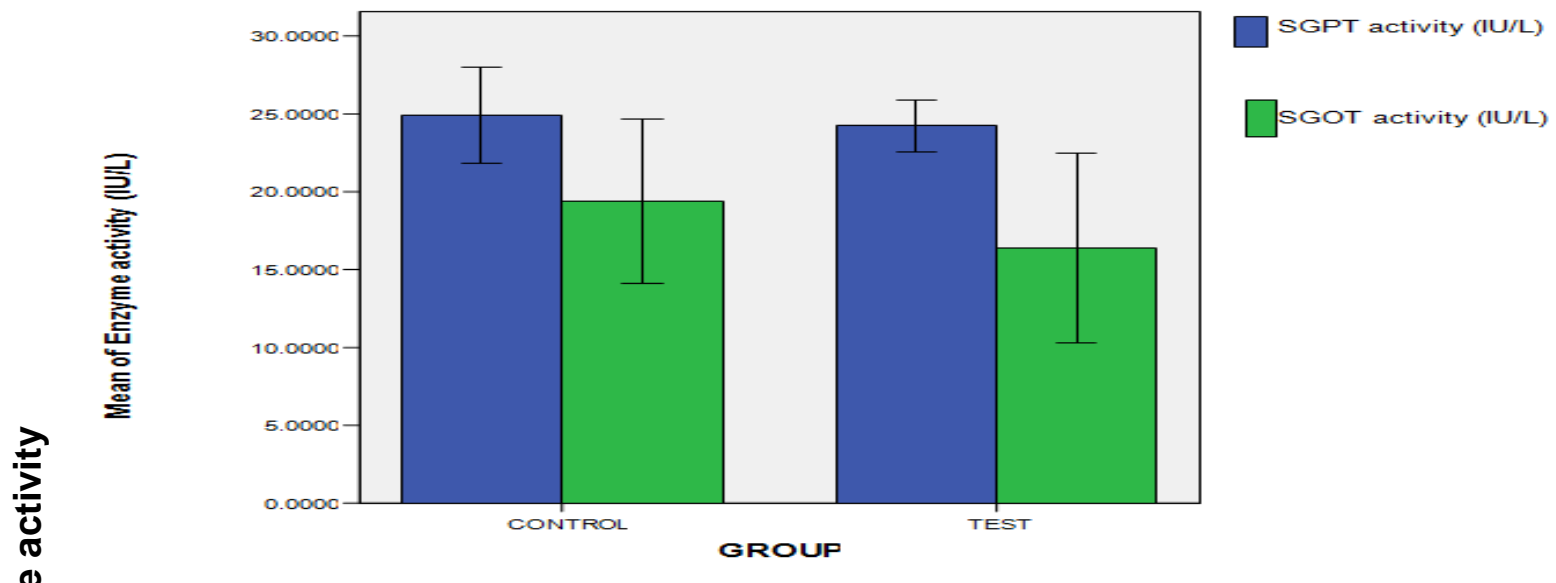

igure 5: Aspartate Amino Transaminase (SGOT) and Alanine Amino Transaminase (SGPT) activity profiles 늘 $(\mathrm{IU} / \mathrm{L})$ in the test and control groups

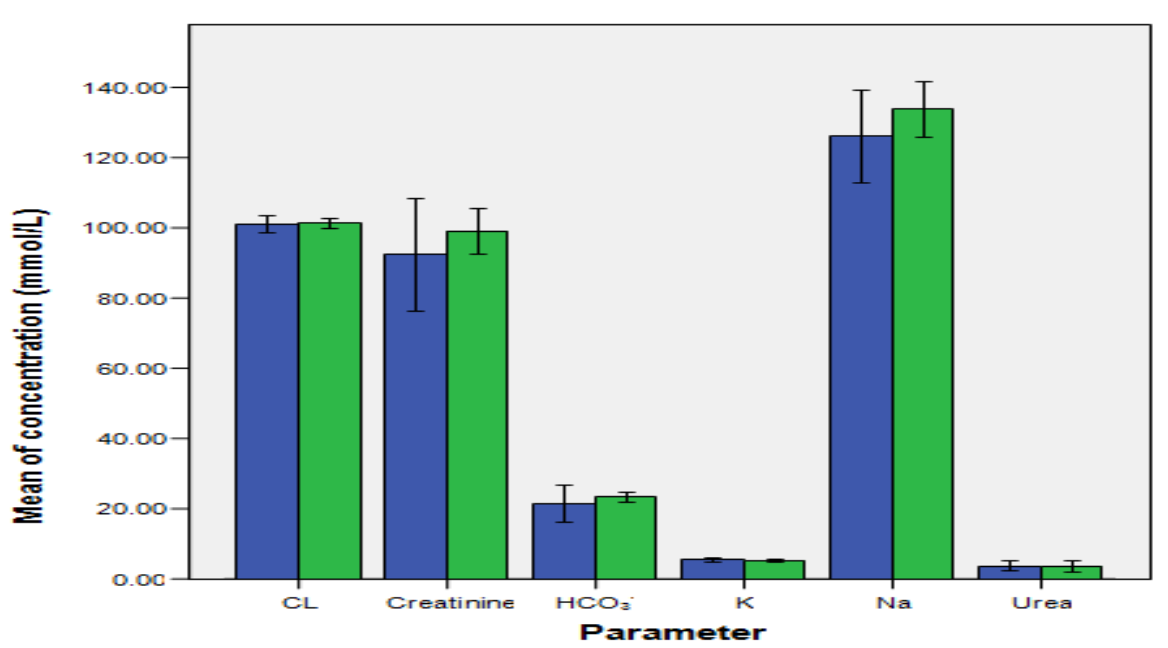

Figure 6: Concentrations of kidney function parameters for animals in the test and control groups. As refers to the Test group; Bs refers to Control group

\subsection{Histopathological profile of the Liver and Kidney of animals administered sub- chronic dose}

Plate 1 shows the micrograph of rat liver at the end of the study period. There is normal hepatic architecture showing central vein and portal tract interphase with hepatic plates separated by sinusoids.

Plate 2 shows the micrograph of rat kidney at the end of the study period.The glomeruli are intact but there appears to be necrosis of the cortex. 
Plate 1: Micrograph of liver at X 100 of rat administered sub chronic dose of crude methanol extract of $E$. camaldulensis (leaf) for three weeks.

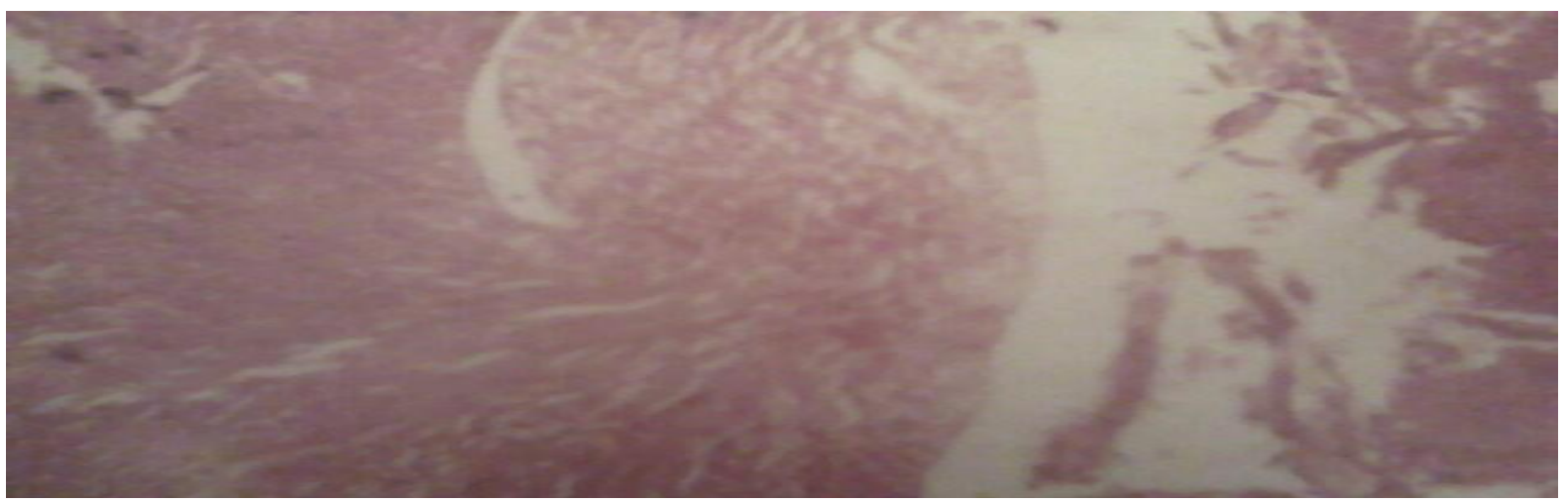

Plate 2: Micrograph of the kidney at X 100 of rat administered $200 \mathrm{mg} / \mathrm{kg}$ bodyweight of methanol extract of $E$. camaldulensis (leaf) for 3 weeks.

\section{Discussion and Conclusion}

Medicinal herbs are moving from fringe to mainstream use with a greater number of people seeking remedies and health approaches free from side effects caused by synthetic chemicals. Recently, considerable attention has been paid to utilize eco-friendly and bio- friendly plant-based products for the prevention and cure of different human diseases.In an earlier study, the methanol extract of E.camaldulensis (leaf) was found not to be acutely toxic because there was no mortality recorded even at the highest dose of 5000mg/kg bodyweight, thus indicating the safety of the extract [13], although there were visible signs of fatigue, shortness of breath, loss of appetite with consequent reduction in feeding (anorexia) and decreased activity in the first 24 hours. All these signs were reversed on the second day and the animals remained normal thereafter. In the present study in which the chronic toxicity of the methanol extract of E.camaldulensis (leaf) was evaluated, the results obtained indicate that the extract given at a uniform dose of $200 \mathrm{mg} / \mathrm{kg}$ bodyweight for three weeks significantly affected some haematological parameters determined and the histopathology of the kidney. The effect of the extract on bodyweight and \% PCV of test animals was not significant bearing in mind the fact that the animals' feeding pattern was not affected to the extent of bringing about low weight. And it appears the extract did not cause lysing of cells that will result in lowering of \% PCV. The differential leucocytes counts, expressed as \% basophils, \% neutrophils and \% eosinophils for animals in the test group experienced changes that were consistent with the normal pattern when animals are exposed to external agents like drugs and medicinal plant extracts. Neutrophils, also known as Granulocytes or segmented neutrophils, are the main defender of the body against infection and antigens. High levels may indicate an active infection; a low count may indicate a compromised immune system or depressed bone marrow (low neutrophil production). Eosinophils are used by the body to protect against allergic reactions and parasites. Therefore, elevated levels may indicate an allergic response. A low count is normal. Basophilic activity is not fully understood but it is known to carry histamine, heparin and serotonin. High levels are found in allergic reactions, low levels are normal. The liver is the principal organ that is capable of converting drugs into forms that can be readily eliminated from the body. A broad spectrum of adverse drug's effects on liver functions and structures has been documented. The reactions range from mild and transient changes in the results of liver function tests to complete liver failure with death of the host. Many drugs may affect the liver adversely in more than one way.

Elevated liver enzymes indicate inflammation or damage to cells in the liver. Inflamed or injured liver cells may leak higher than normal amounts of certain chemicals, including liver enzymes, into the bloodstream, resulting in elevated liver enzymes on blood tests. The specific elevated liver enzymes most commonly found are: Alanine Amino transferase (ALT) and Aspartate transaminase (AST). In most cases, liver enzyme levels are elevated mildly and temporarily. Most of the time, elevated liver enzymes don't signal a chronic, serious liver problem. Low levels of ALT are normally found in the blood. But when the liver is damaged or diseased, it releases ALT into the bloodstream, which makes ALT levels go up. Most increases in ALT levels are caused by liver damage In this study, we observed that there was a significant difference between ALT activities in the control and test groups. The enzyme activity was lower for the test group that was administered the crude extract. This observation indicates a likely damage to the liver that ultimately affected the enzyme by lowering its activity but the results obtained from the histopathological studies of the liver did not substantiate this observation because there was no observable hepatocyte damage on the sectioned and stained liver slides. There 
was no visible effect of the extract on the liver cells because the normal hepatic architecture showing central vein and portal tract interphase with hepatic plates separated by sinusoids was maintained (Plate 1). On the other hand, the activities of AST in the control and test groups were not significantly different (Figure 1). AST levels fluctuate in response to the extent of cellular necrosis (cell death) and therefore may be temporarily and minimally elevated early in the disease process, and extremely elevated during the most acute phase. Depending on when the initial sample was drawn, AST levels can rise- indicating increasing disease severity and tissue damage- or fall- indicating disease resolution and tissue repair. Thus, the relative change in AST values serves as a reliable monitoring mechanism [14]. Some determinations that were carried out determine the effect of the extract on the concentrations of electrolytes and metabolites indicate insignificant differences between the concentrations of $\mathrm{Na}+, \mathrm{Cl}-, \mathrm{HCO}-, \mathrm{K}$, Urea and Creatinine for the test and control groups. This indicates that the kidney was not affected by the extract in terms of maintaining the electrolyte balance in the blood and clearance profile of Urea and Creatinine.Histopathologically, the liver was spared of any negative effect of the extract as shown in plate 1 , while the kidney cells were affected to the extent of causing necrosis of the cortex (plate 2). It is however difficult to link this phenomenon to the elevation in the serum activity of AST because the necrosis is not very pronounced.It can be concluded from the results obtained in this study that though the leaves of E. Camaldulensis is reported to have antiplasmodial activity[13], it must be used with a high degree of caution in view of possible long-term effects on some sensitive organs of the body.

\section{Acknowledgements}

This work was funded by a research grant to Emmanuel O. Ogbadoyi by the Organization for the Prohibition of Chemical Weapons (Hague) and a STEP-B grant to the Federal University of Technology, Minna, Nigeria

\section{References}

[1]. World Health Organization (2008). Traditional Medicine. Fact sheet no. 134

[2]. Gamaliel, K. S. (2000). Toxicity from medicinal plants and their products. Nig. J. Nat. Prod. and Med. 4: 4- 5.

Groves, M. J. and Bisset, N. G. (1991). A note on the use of topical digitalis prior to William Withering, Journal of Ethno pharmacology 35: 99-103.

[3]. Gijtenbeek, J. M. M., Vanden Bent, M. J. and Vecht, C. J., Cyclosporin neurotoxicity. J. Neurol., 1999, $246,339-346$.

[4]. Johnson, W. C. and William, O. W., Warfarin toxicity. J. Vasc. Surg., $2002413-421$.

[5]. Bodeker, G. (1998). The therapeutic potential of plants used as traditionally as antimalarials: New directions of research. In : Health in the Common Wealth, Kinsington press. Pp.120-125.

[6]. Batish, D. R; Singh, H. P; Kohli, R. K and Kaur, S. Eucalyptus essential oil as a natural pesticide http//www.eucalypt.oil. 2008.

[7]. Canadian Council on Animal Care (CCAC).1997. Guidelines on: Animal use and Protocol Review

[8]. Ogbadoyi EO, Garba MH, Kabiru AY, Mann A, Okogun JI (2011) Therapeutic evaluation of Acacia nilotica (Linn) stembark extract in experimental African trypanosomiasis International Journal of Applied Research in Natural Products

Vol. 4 (2), pp. 11-18, June-July 2011

[9]. Blessing U. Ugwu, Joseph I. Okogun, Adamu Y. Kabiru and Emmanuel O. Ogbadoyi. Evaluation of Therapeutic Potentials of Stem Bark Extracts of Annona senegalensis in Experimental Trypanosoma brucei brucei Infection in Mice. British Journal of Pharmacology and Toxicology. 2011. 2(2): 63-70.

[10]. International Federation of Clinical Chemistry (IFCC).1976. Determination of Alanine Amino Transferase (ALT) or Serum Glutamate-Pyruvate Transaminase (SGPT) Activity

[11]. International Federation of Clinical Chemistry (IFCC). 1980. Determination of Aspartate AminoTransferase (AST) or Serum Glutamate - Oxaloacetate Transaminase (SGOT) Activity

[12]. Wallace, H. A. 2001. Principles and Methods of Toxicology. Raven Press, New York. p. 45-345

[13]. Kabiru, Y. A, Okogun, J. I, Gbodi, T. A, Makun, H. A and Ogbadoyi, E.O. 2012. Evaluation of the efficacy of combination therapy in T. b .brucei - infected mice using extracts of annona senegalensis and eucalyptus camaldulensis. IOSR Journal of Pharmacy ISSN: 2250-3013, www.iosrphr.org Volume 2 Issue 4. PP.32-37

[14]. Ferri, F.F. (2009). Ferri's Clinical Advisor 2009. Philadelphia, Pa.: Mosby Elsevier; pp.1434. 